\title{
Relationship between Interannual Variations of Extreme Hourly Precipitation and Air/Sea-Surface Temperature in Japan
}

\author{
Fumiaki Fujibe \\ Meteorological Research Institute, Tsukuba, Japan
}

\begin{abstract}
Long-term changes in extreme hourly precipitation in Japan were examined using data at 983 stations for 1979 to 2013, with relation to the variations in air temperature (AT) and sea-surface temperature (SST). According to the statistics over the whole country, annual maximum and 95 percentile precipitations show increasing trends of $2-4 \% /$ decade, whereas AT and SST have risen at a rate of $0.2-0.3^{\circ} \mathrm{C} /$ decade. Analysis for each region and season indicates that the increase in extreme precipitation is a nation-wide feature and is not limited to a single season. Moreover, year-to-year variations in extreme precipitation tend to be in phase with those of AT and SST, with a correlation coefficient of $0.5-0.6$ on the annual basis, although negative correlation is found for the
\end{abstract} summer season in western Japan and the Nansei Islands.

(Citation: Fujibe, F., 2015: Relationship between interannual variations of extreme hourly precipitation and air/sea-surface temperature in Japan. SOLA, 11, 5-9, doi:10.2151/sola.2015-002.)

\section{Introduction}

It is believed that more intense precipitation is encountered under warmer climate due to larger amount of saturation vapor pressure, which increases with temperature at a rate of $6-7 \% / \mathrm{K}$ as given by the Clausius-Clapeyron (CC) formula. A number of statistical studies have revealed the increase of extreme precipitation intensity with temperature on the basis of percentiles defined for each temperature range, although the rate of increase may deviate from the CC relationship (Berg et al. 2009, 2013; Lenderink and van Meijgaard 2010; Berg and Haerter 2013; Utsumi et al. 2011).

In the context of climate change, intense precipitation has been found to have increased in many regions of the world as expected from the increase of mean temperature (e.g., IPCC 2013; Fujibe et al. 2006), although 'many regions present statistically non-significant or negative trends' (IPCC 2013). While these findings are mostly based on daily data, Lenderink et al. (2011) showed coherent variations in extreme hourly precipitation and dew-point temperature (15 year running averages) at De Bild in the Netherlands and for the cold season at Hong Kong. Fujibe (2013) showed a similar feature for extreme ten-minute and hourly precipitation in Japan for 1951 to 2010. In these two studies, the rate of increase in extreme precipitation to temperature is nearly the same as, or slightly higher than the $\mathrm{CC}$ rate.

For seasonal and year-to-year variations, however, the relationship of extreme precipitation and temperature may be less evident. On such a time scale, precipitation is likely to be controlled by the activity of synoptic disturbances such as tropical cyclones and frontal systems, which will be closely linked to large-scale atmospheric and oceanic dynamics rather than to local temperature. Nevertheless, Fujibe (2013) found weak but statistically significant correlation between yearly values of extreme short-time precipitation and annual-mean temperature in Japan, each defined by deviation from the five-year running average.

Fujibe et al. (2006) and Fujibe (2013) used data from less than a hundred stations, for which data of sixty years or more were available. However, spatial data density is another important

Corresponding author: Fumiaki Fujibe, Meteorological Research Institute, 1-1 Nagamine, Tsukuba 305-0052, Japan. E-mail: ffujibe@mri-jma.go.jp. (C) 2015, the Meteorological Society of Japan. factor in identifying the features of extreme precipitation, which is highly sporadic and spatially heterogeneous. In the present study, data from nearly a thousand stations were used for detailed analysis of the relationship between interannual variations of extreme precipitation and temperature in Japan, including regional and seasonal features, at some cost of data length.

In recent years, the relationship of intense precipitation in Japan and nearby sea-surface temperature (hereafter SST) has attracted attention of researchers. For example, Tsuguti and Kato (2014) discussed the effect of high SST in a case of heavy rainfall on an island south of Kyushu. A number of modeling studies have examined the relationship between SST variation and extreme or seasonal mean precipitation with relation to the CC effect (Manda et al. 2014; Takahashi et al. 2013). In the present study, therefore, analysis for SST was made in addition to air temperature (AT).

\section{Data}

The study was based on hourly precipitation data of the Automated Meteorological Data Acquisition System (AMeDAS), which was deployed in the late 1970s by the Japan Meteorological Agency (JMA) with about 1300 raingauges in Japan. The analysis was made for the 35 years from 1979 to 2013. Analysis was made mainly for extreme hourly precipitation, but was made also for six-hour and 24-hour accumulated precipitations for the sake of comparison.

Each station used for analysis was required to provide data for at least 30 years for any one of the twelve months, on a condition that a month with missing records of more than $3 \%$ was regarded as unusable. The resulting number of stations available was 983, as shown in Fig. 1. The area of Japan was divided into four regions consisting of northern Japan, eastern Japan, western Japan, and the Nansei Islands, according to the JMA's regional division for climate information. The number of stations in these regions is $327,295,334$, and 27 , respectively.

Precipitation observation at AMeDAS stations has been made using a tipping-bucket raingauge, with precision of either $0.5 \mathrm{~mm}$ or $1 \mathrm{~mm}$. Since the tipping bucket raingauge incrementally measures precipitation accumulation, precipitation of a half-integer value $(2.5 \mathrm{~mm}$, for example) will be recorded as either of the neighboring integer values $(2 \mathrm{~mm}$ or $3 \mathrm{~mm})$ with an equal chance if a raingauge of $1 \mathrm{~mm}$ precision is used. In the present study, therefore, a half-integer record was treated as a mixture of neighboring integer records with a half weight, in order to avoid inhomogeneity due to the difference in raingauge precision.

The analysis of extreme precipitation was based on two kinds of indices. One is the maximum hourly precipitation (hereafter $\left.\mathrm{P}_{\max }\right)$ at a station in a year. The other index is the 95 percentile value (hereafter $\mathrm{P}_{95}$ ) among hourly data of $\geq 1 \mathrm{~mm}$ precipitation at a station in a year. Annual third and tenth largest hourly precipitation, and 99 and 90 percentiles were also analyzed, but the results have essentially the same feature as those obtained from $\mathrm{P}_{\max }$ and $\mathrm{P}_{95}$. In addition, the total precipitation amount (PTOT) and hours of $\geq 1 \mathrm{~mm}$ precipitation $(\mathrm{H} 1 \mathrm{~mm})$ were defined. All of these indices were averaged over stations in the whole country or in each region defined above. As an index of precipitation intensity, the ratio of areal averages in PTOT and $\mathrm{H} 1 \mathrm{~mm}$ was used under the name of "simple hourly intensity index" (SHII).

In monthly analysis, precipitation indices were calculated for three consecutive months instead of a whole year. There are two reasons for using data of three months instead of a single month. 


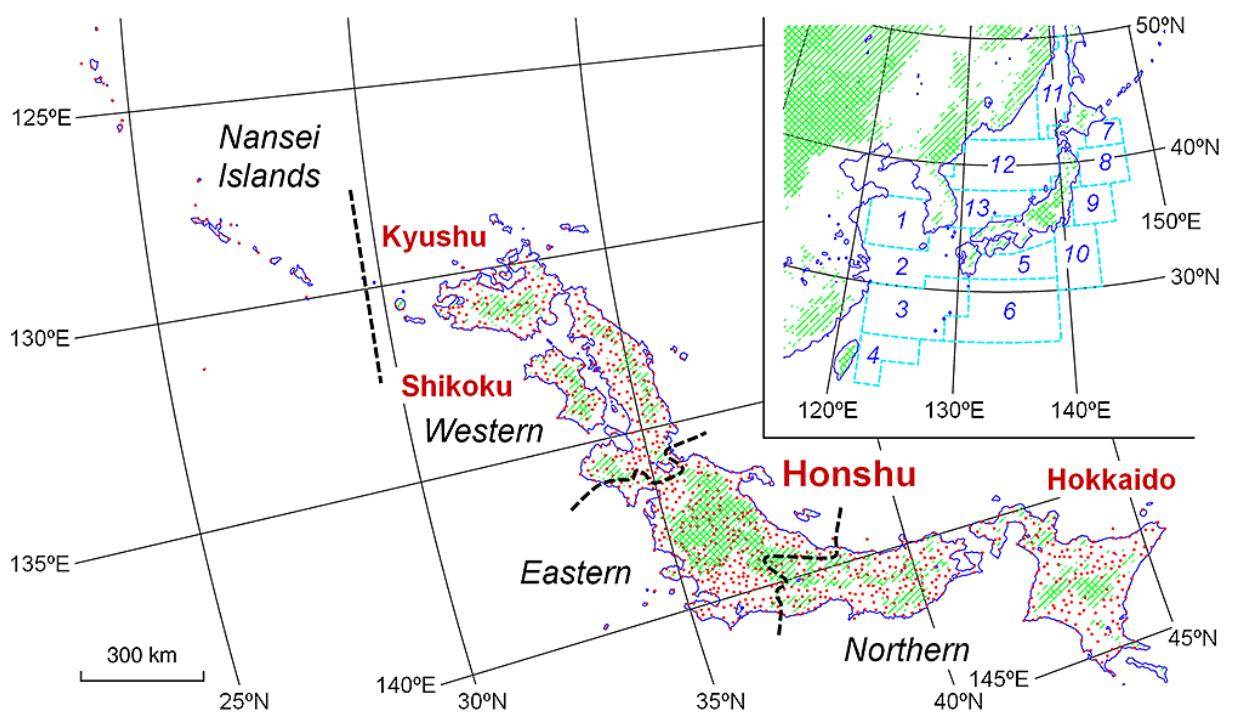

Fig. 1. Distribution of AMeDAS stations used for analysis (red dots), and division of regions for analyses of precipitation and AT (black dashed lines). The upper right panel shows the areas of SST data provided by JMA. Green hatching indicates the area above $500 \mathrm{~m}$, and double hatching indicates the area above $1000 \mathrm{~m}$ in elevation.
One is consistency with the SST data, which were available only in three-month averages. The other is to reduce statistical uncertainty arising from a small sample size.

For air temperature (hereafter AT), monthly and regionally averaged values were obtained from the webpage of the JMA (http://www.data.jma.go.jp/cpdinfo/db/database_temp.html, http:// www.data.jma.go.jp/gmd/cpd/cgi-bin/view/index.php). Data of seasurface temperature (SST) were also obtained from the JMA's webpage (http://www.data.jma.go.jp/gmd/kaiyou/data/shindan/a 1/ japan_warm/japan_warm_data.html), which provides three-month mean (JFM, AMJ, JAS, and OND) and annual mean values for 13 areas around Japan (Fig. 1). For the same reason as for precipitation, monthly analysis for AT was made using an average over three consecutive months. It is to be noted that some stations used for compiling temperature data are in medium-sized cities, so that long-term temperature trends may be biased by urban warming (Fujibe 2012). However, correction to urban warming was not made because accurate evaluation of temperature trends was not of major interest of the study.

\section{Regional and seasonal features of extreme precipi- tation trends}

Figure 2 shows the interannual variations of $\mathrm{P}_{\max }$ and $\mathrm{P}_{95}$ for hourly precipitation, as well as AT and SST, on the basis of annual statistics for the whole region. Analysis of SST was made by simply averaging the data in all the regions in Fig. 1 except Region 1. The linear trend of each quantity was calculated from the leastsquares criterion

$$
\sum_{n}\left\{P(n)-\left[A+B\left(n-\frac{n_{1}+n_{2}}{2}\right)\right]\right\}^{2} \rightarrow \min ,
$$

where $P(n)$ is the value of each quantity in year $n, n_{1}$ and $n_{2}$ are the first and last years of the analysis period (namely, 1979 and 2013), and $A$ and $B$ are the least-squares coefficients. Hereafter, the relative trend $(B / A)$ is used for precipitation indices, and the absolute trend $(B)$ is used for temperature. In Fig. 2, all the four quantities have positive trends, with an increasing rate of $3.6 \%$ / decade for $\mathrm{P}_{\max }$ and $2.3 \%$ decade for $\mathrm{P}_{95}$, while the temperature trend is $0.29^{\circ} \mathrm{C} /$ decade for AT and $0.21^{\circ} \mathrm{C} /$ decade for SST. These values are significant at the $1 \%$ level.

Figure 3 shows the linear trends of these four parameters, as well as PTOT and SHII, for each month and region. For SST, the average for Regions 7, 8, 11, and 12 was used for northern Japan, Regions 9, 10, 12, and 13 for eastern Japan, Regions 2, 5, 6, and 13 for western Japan, and Regions 3, 4, and 6 for the Nansei

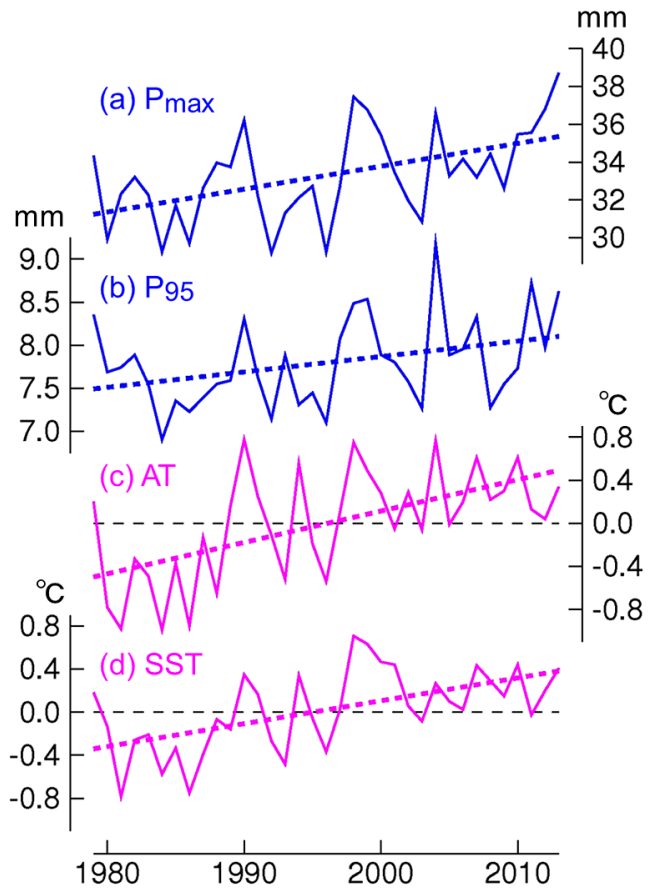

Fig. 2. Year-to-year variations of $\mathrm{P}_{\max }$ (annual maximum) and $\mathrm{P}_{95}$ (based on annual data) for hourly precipitation, and of AT and SST (annual mean of deviation from the 1981-2010 average), each averaged over the whole country. Dashed lines indicate linear trends.

Islands. For the annual statistics, $\mathrm{P}_{\max }$ has positive trends of about $3 \% /$ decade, which is significant at the $5 \%$ level, except for the Nansei Islands. On the monthly basis, statistically significant trends are found for part of months in summer to early autumn, and January. It is to be noted that trends of the same order as these are found also in late autumn and early winter, but they are not significant because of a larger confidence range, which may reflect the higher sporadicity of extreme precipitation in cold seasons than in summer. Similar features are found for $\mathrm{P}_{95}$, although statistical significance tends to be lower than that for $\mathrm{P}_{\max }$.

On the other hand, trends of PTOT are insignificant except for part of winter months. The features of SHII are similar to those of $\mathrm{P}_{\max }$ and $\mathrm{P}_{95}$, with trends for eastern Japan $(2.2 \%$ /decade) and the Nansei Islands $(2.0 \% /$ decade) significant at the $5 \%$ level, and for the whole area (1.5\%/decade) and northern Japan (1.6\%/decade) significant at the $10 \%$ level, on the annual statistics. 

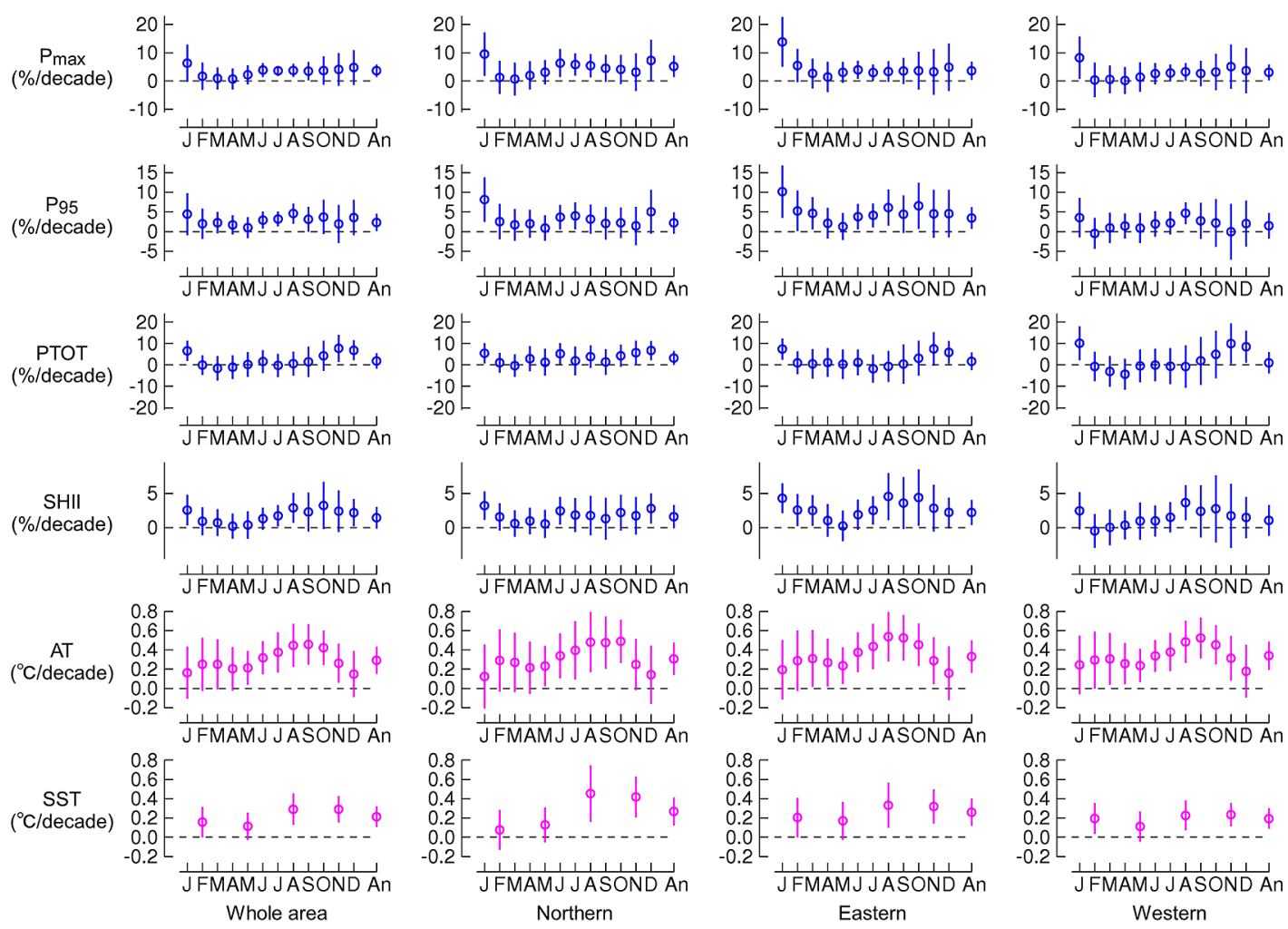

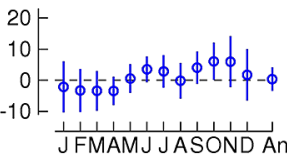
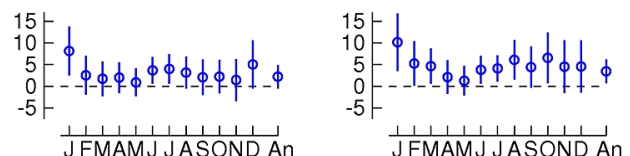

5

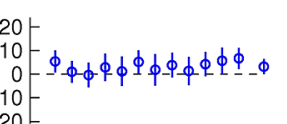

$\frac{1+11+1-1+1}{J \text { JMMAMJ JASOND An }}$

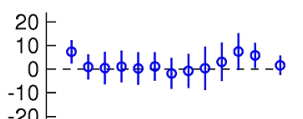

1111111111111111
JFMAMJ JASOND An

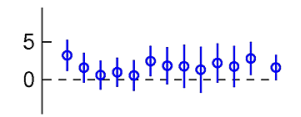

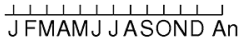
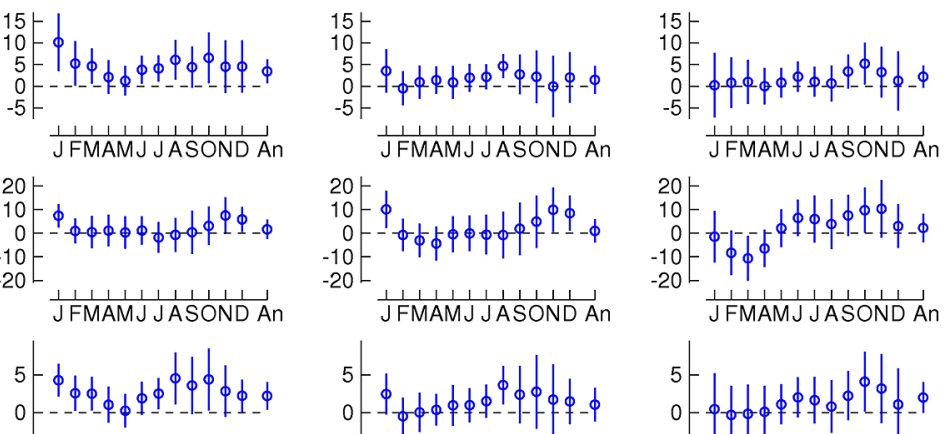

$\frac{111111111111}{\text { JFMAMJ JASOND An }}$

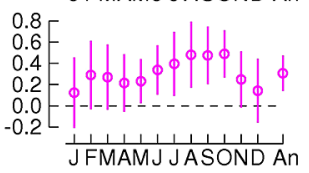

$111+11-11111$
JFMAMJ J ASOND An
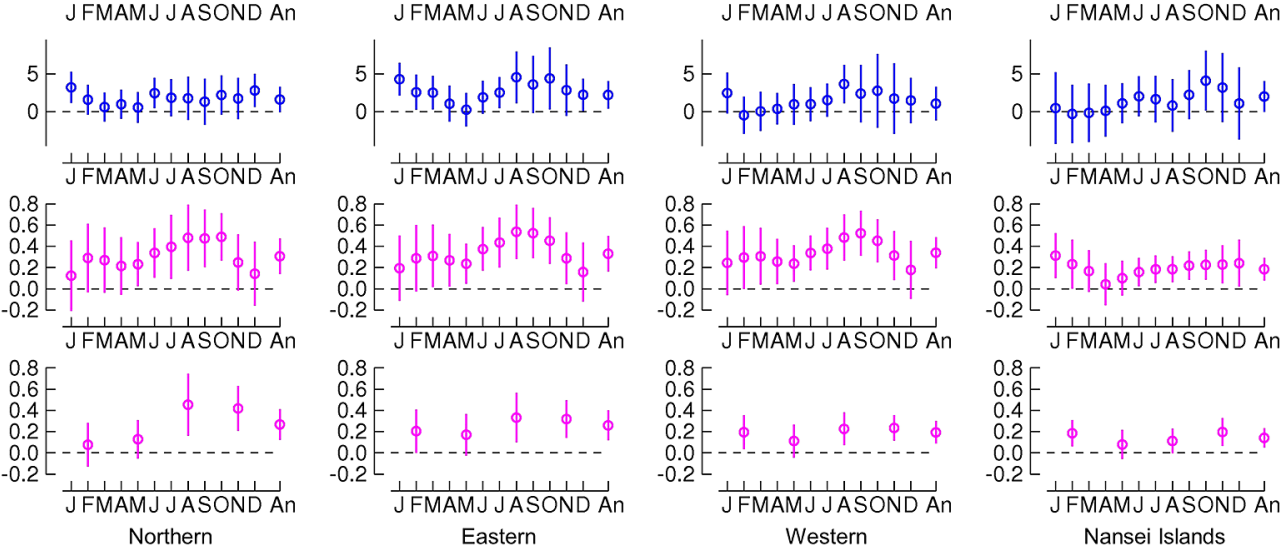

11111111111
JFMAMJ JASOND An

0.8 [
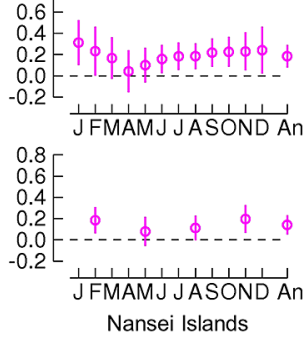

Fig. 3. Linear trends of each parameter for each region and month. The value based on the annual statistics is shown as 'An' on the right of each panel. Vertical bars indicate the $95 \%$ confidence range.

Trends of AT and SST are positive in all the regions and seasons, and are statistically significant except for part of winter and spring months. Except the Nansei Islands, trends are largest from late summer to early autumn. This seasonality seems to reflect the increase of hot summers in the recent decade, although data for the period of over a hundred years indicate a lowest rate of warming in summer among the four seasons (JMA 2013).

Figure 4 shows the trends of $\mathrm{P}_{\max }$ for six-hour and 24-hour precipitation on the annual statistics over the whole area. The trend is $2.8 \%$ /decade for six-hour precipitation, and $3.0 \% /$ decade for 24-hour precipitation. For $\mathrm{P}_{95}$ (not shown), trends are $2.3 \%$ / decade and $2.1 \% /$ decade, respectively. Due to year-to-year variabilities that are larger than those of hourly precipitation, the trends for six-hour precipitation are significant only at the $10 \%$ level, whereas those of 24-hour precipitation are insignificant even at the $10 \%$ level. Thus the trend of extreme precipitation of a longer time scale tends to have weaker statistical significance, although the magnitude of the trend may be close to that of hourly precipitation.

\section{Correlation in year-to-year variations of extreme precipitation and temperature}

In addition to long-term linear trends, Figure 2 shows considerable interannual variations that are partly coherent between indices in precipitation and temperature. This fact indicates that a year of positive anomaly in AT and/or SST tends to experience more intense precipitation than a year of negative temperature anomaly.

In this section, departure from the linear trend of each quantity is used in order to focus on year-to-year variations. Figure 5 shows scatter diagrams of extreme precipitation $\left(\mathrm{P}_{\max }, \mathrm{P}_{95}\right.$ for hourly precipitation) and temperature (AT, SST) on the annual statistics over the whole area. It can be seen that $\mathrm{P}_{\max }$ is correlated to AT and SST with a coefficient of 0.56 and 0.62 , respectively. The corresponding rate of change in $\mathrm{P}_{\max }$ with AT is $8.7 \pm 4.6 \% / \mathrm{K}$,

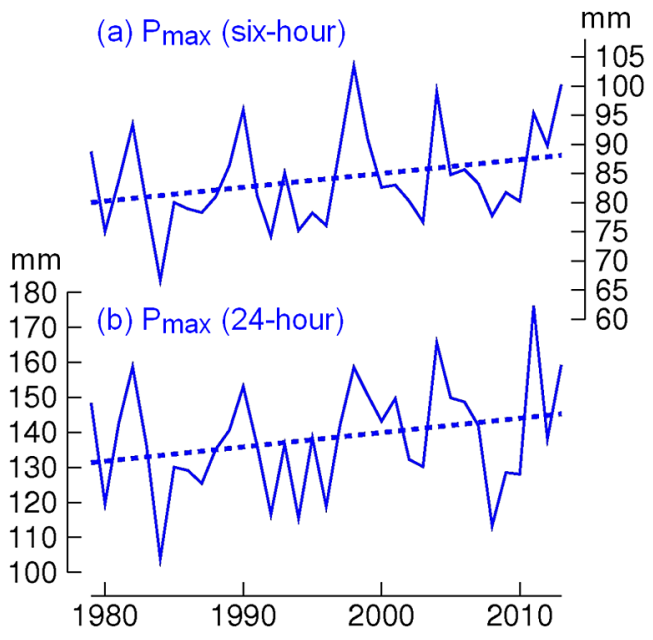

Fig. 4. Same as Fig. 2, but for Pmax for six-hour and 24-hour precipitation.

and that with SST is $12.9 \pm 5.8 \% / \mathrm{K}$, where " \pm " indicates the $95 \%$ confidence range. Likewise, $\mathrm{P}_{95}$ is correlated to AT and SST with coefficients of 0.50 and 0.47 , respectively, and the rate of change with AT and SST is $7.6 \pm 4.7 \% / \mathrm{K}$ and $9.5 \pm 6.7 \% / \mathrm{K}$, respectively. All of these values are significant at the $1 \%$ level.

Figure 6 shows the correlation coefficients between precipitation and temperature for each region and month. Positive correlations between $\mathrm{P}_{\max }$ and AT are found for northern Japan and eastern Japan, not only for annual values but also for months in summer to autumn and late winter. For western Japan and the Nansei Islands, correlation is positive for part of autumn and winter months, but is negative for part of summer months with a significance of the $10 \%$ level. The situation is almost the same for the correlation between $\mathrm{P}_{95}$ and AT, except the absence of negative 
correlation in summer in western Japan and the Nansei Islands, and the presence of positive correlation for the annual statistics in the Nansei Islands. Similar features are found also for the correlation between SHII and AT, with respect to positive correlation for the annual statistics except western Japan, and in autumn and winter. For PTOT, significant positive correlation is limited to northern Japan and the Nansei Islands on the annual statistics, and part of autumn and winter months, whereas negative correlation is found in summer for all the regions. The situation changes only a little if SST is used instead of AT.

Figure 7 shows scatter diagrams of $\mathrm{P}_{\max }$, for six- and 24-hour precipitations and temperature on the annual statistics over the
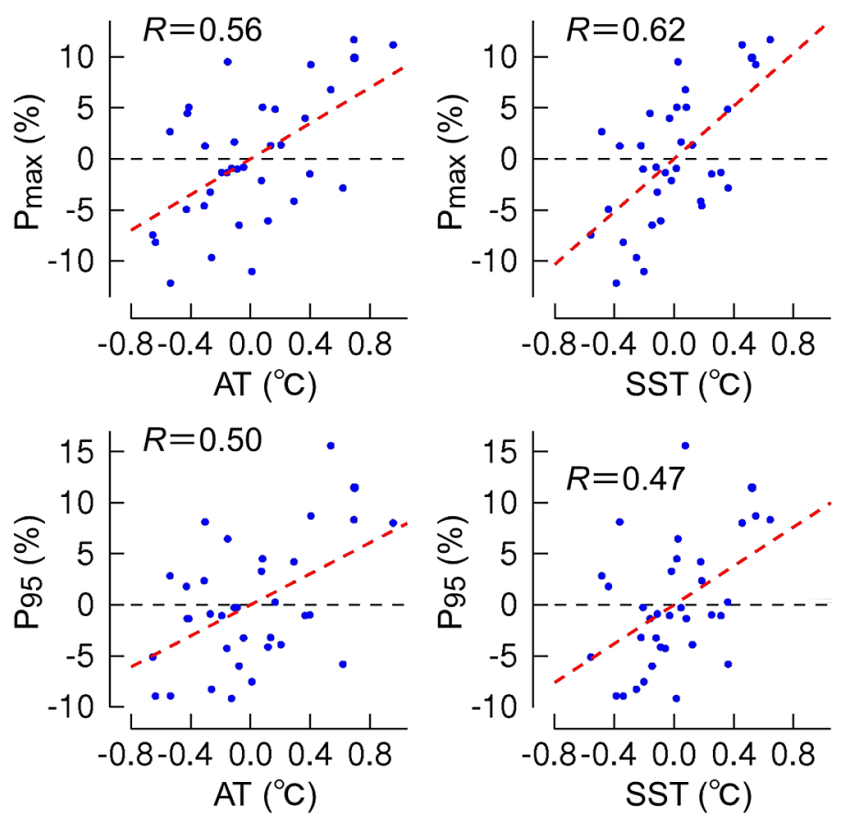

Fig. 5. Scatter diagram of extreme precipitation index $\left(\mathrm{P}_{\max }\right.$ or $\mathrm{P}_{95}$ for hourly precipitation) and temperature (AT or SST) on the annual statistics for the whole area. Each dot indicates an annual value. The red dashed line indicates the linear regression, and $R$ is the correlation coefficient. whole area. There are positive correlations of 0.3 to 0.5 , with a significance of $5 \%$ for six-hour precipitation, and $10 \%$ for 24 -hour precipitation. In comparison to the results for hourly precipitation (Fig. 5), correlation tends to be lower, and so is statistical significance. The situation is similar for regional and seasonal statistics (not shown).

\section{Discussions}

The present study has confirmed the increase of extreme hourly precipitation in Japan since the 1980s. The rate of increase
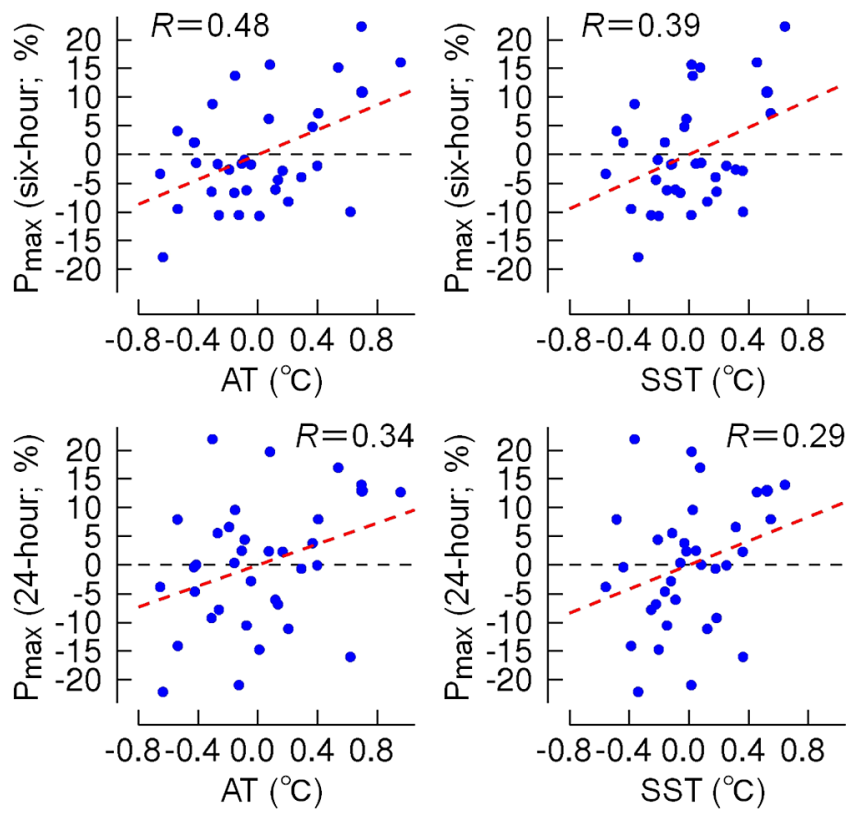

Fig. 7. Same as Fig. 5, but for Pmax for six-hour and 24-hour precipitation.

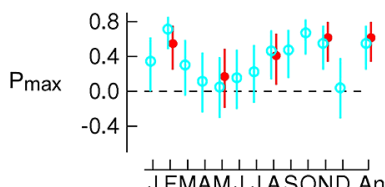

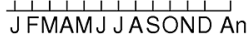

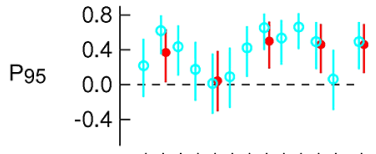

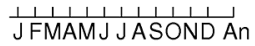

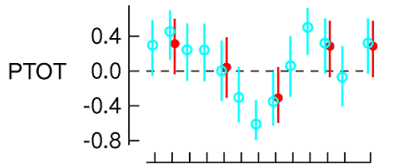

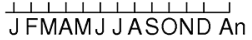

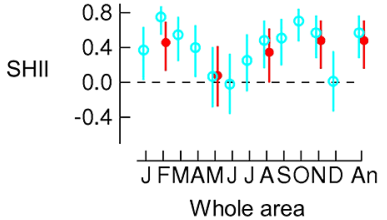

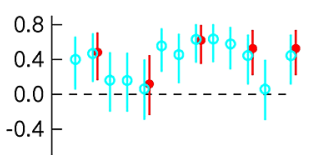

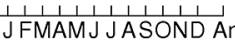

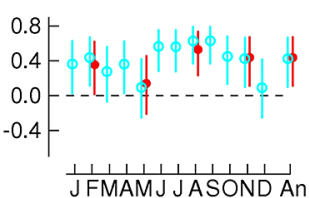

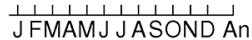
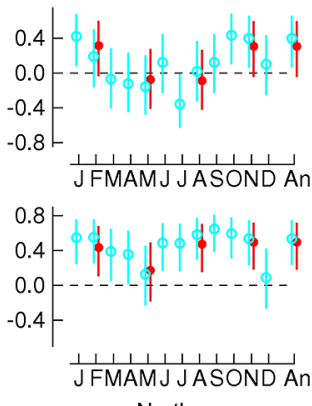
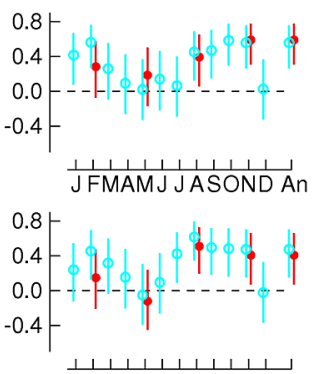

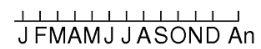

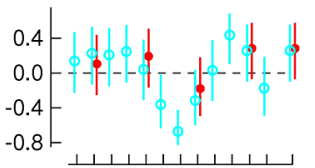

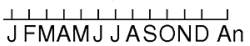

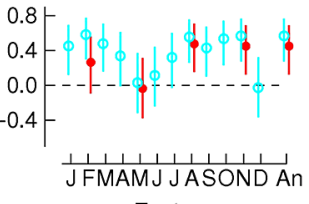

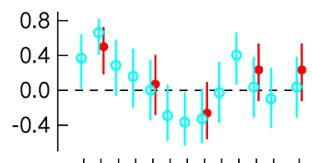

$\frac{1111+1-111111}{\text { JFMAMJ J ASOND An }}$

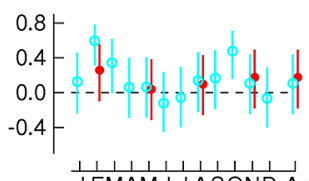

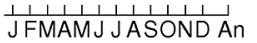
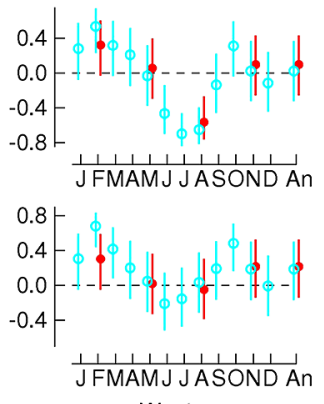

Western

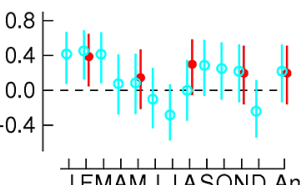

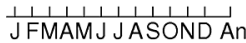

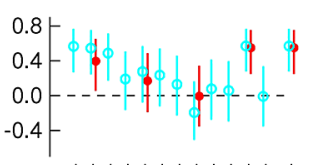

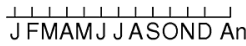

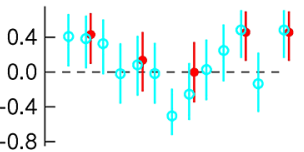

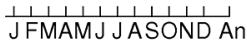

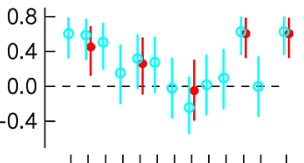

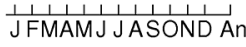

Nansei Islands

Fig. 6. Correlation coefficients between each parameter and AT (blue open circles), and SST (red closed circles) for each region and month. Symbols have been shifted left or right to avoid overlapping. The meanings of 'An' and vertical bars are the same as in Fig. 3. 
in $\mathrm{P}_{\max }$ and $\mathrm{P}_{95}$ is $2-4 \%$ /decade, which is consistent with the value obtained by Fujibe (2013) for a smaller number of stations than the present study. It is to be noted that the rate of temperature change is variable on a multidecadal time scale, and the analysis period of the present study is characterized by both a higher rate of warming and a larger rate of increase in extreme precipitation than before (Fujibe 2013).

The regional analysis (Fig.3) has revealed the absence of strong regionality in trends of $\mathrm{P}_{\max }$ and $\mathrm{P}_{95}$. As for seasonality, statistically significant trends in extreme precipitation are mainly found from summer to early autumn, but apart from statistical significance, positive trends are found in other seasons as well, except spring. It may be possible to hypothesize that the increase of extreme precipitation is a nation-wide and year-round feature, although its statistical confirmation is a future task.

Another interesting aspect of the present study is the positive correlation between extreme precipitation indices and temperature (AT and SST) in year-to-year variations (Figs. 5 and 7). This fact implies that the CC effect is valid even in interannual and seasonal variations. This correlation may arise from the influence of SST, which is characterized by slower changes than atmospheric circulation systems. However, an attempt to separate the contribution of AT and SST on precipitation was unsuccessful due to their high collinearity. In fact, the coherence of AT and SST is as large as 0.79 on the annual statistics over the whole area, so that a partial correlation analysis resulted in hardly any statistically significant signals (not shown).

Quantitatively, the rate of change in extreme precipitation with respect to temperature variation appears to be larger than the $\mathrm{CC}$ rate (namely, a super-CC rate), although statistically significant departure from the $\mathrm{CC}$ rate is found only for the relation between $\mathrm{P}_{\max }$ and SST (Fig. 5). Some previous studies have also documented super-CC relationship between extreme precipitation and temperature (Berg et al. 2013; Lenderink and van Meijgaard 2010; Berg and Haerter 2013; Lenderink et al. 2011; Fujibe 2013), although the reason for departure from the $\mathrm{CC}$ rate is still under discussion.

It is to be noted that the total precipitation (PTOT) is less significantly correlated with temperature on the annual statistics (Fig. 6). This fact implies that year-to-year variation in total precipitation is more strongly linked to that of large-scale circulation, whereas extreme precipitation, namely the peak intensity of precipitation, is more closely related to local temperature. It is also to be noted that extreme precipitation of a longer time scale tends to have weaker correlation with temperature, both in magnitude and in statistical significance (Fig. 7). As suggested in some previous studies (e.g., Utsumi et al. 2011), extreme precipitation of a shorter time scale is likely to exhibit the CC effect more explicitly, as a result of weaker influence of the variation of dynamical fields.

This discussion does not mean, however, that the variation of extreme hourly precipitation is unaffected by the large-scale field. A remarkable feature in our result is the negative correlation between extreme precipitation and temperature for western Japan and the Nansei Islands in summer (Fig. 6). The summer of these regions is controlled by the subtropical high, and a hot summer tends to have less precipitation under the dominance of the high. The negative correlation between precipitation and temperature is likely to be explained by a smaller chance of precipitation in a hotter summer, which overwhelms the CC effect.

Finally, a simple analysis was made for teleconnection indices that are often discussed in relation to extreme precipitation in Japan, using data provided by JMA. It was found that $\mathrm{P}_{\max }$ is negatively correlated to the Pacific Decadal Oscillation index (PDO; http://www.data.jma.go.jp/kaiyou/data/shindan/b 1/pdo/pdo. html), with a correlation coefficient of -0.49 on the annual statistics for the whole country. This fact is consistent with the positive correlation between extreme precipitation and temperature, because a positive phase of PDO is associated with negative SST anomaly around Japan. However, correlations between extreme precipitation and indices related to El Niño Southern Oscillation (ENSO; http://www.data.jma.go.jp/kaiyou/data/shindan/b_1/pdo/ pdo.html), such as the Southern Oscillation Index, Nino-3 SST and Nino-west SST, are mostly insignificant. This fact implies that the intensity of extreme precipitation is related to temperature (AT and SST) in and around Japan more closely than to the large-scale circulation in the tropical Pacific.

\section{Acknowledgments}

This study was supported by "Funds for integrated promotion of social system reform and research and development" by the Ministry of Education, Culture, Sports, Science and Technology of Japan.

\section{References}

Berg, P., and J. O. Haerter, 2013: Unexpected increase in precipitation intensity with temperature. A result of mixing of precipitation types? Atmos. Res., 119, 56-61.

Berg, P., J. O. Haerter, P. Thejll, C. Piani, S. Hagemann, and J. H. Christensen, 2009: Seasonal characteristics of the relationship between daily precipitation intensity and surface temperature. J. Geophys. Res., 114, D18102, doi:10.1029/2009 JD012008.

Berg, P., C. Moseley, and J. O. Haerter, 2013: Strong increase in convective precipitation in response to higher temperatures. Nat. Geosci., 6, 181-185.

Fujibe, F., 2012: Evaluation of background and urban warming trends based on centennial temperature data in Japan. Pap. Meteor. Geophys., 63, 43-56.

Fujibe, F., 2013: Clausius-Clapeyron-like relationship in multidecadal changes of extreme short-term precipitation and temperature in Japan. Atmos. Sci. Lett., 14, 127-132.

Fujibe, F., N. Yamazaki, and K. Kobayashi, 2006: Long-term changes of heavy precipitation and dry weather in Japan (1901-2004). J. Meteor. Soc. Japan, 84, 1033-1046.

IPCC, 2013: Climate Change 2013: The Physical Science Basis. Contribution of Working Group I to the Fifth Assessment Report of the Intergovernmental Panel on Climate Change. Cambridge University Press, $1535 \mathrm{pp}$.

Japan Meteorological Agency, 2013: Climate Change Monitoring Report 2012. JMA, 74pp. (available from http://www.jma. go.jp/jma/en/NMHS/indexe_ccmr.html)

Lenderink, G., and E. van Meijgaard, 2010: Linking increases in hourly precipitation extremes to atmospheric temperature and moisture changes. Environ. Res. Lett., 5, 025208, doi: 10.1088/1748-9326/5/2/025208

Lenderink, G., H. Y. Mok, T. C. Lee, and G. J. van Oldenborgh, 2011: Scaling and trends of hourly precipitation extremes in two different climate zones. -Hong Kong and the Netherlands. Hydrol. Earth Syst. Sci., 15, 3033-3041.

Manda, A., H. Nakamura, N. Asano, S. Iizuka, T. Miyama, Q. Moteki, M. K. Yoshioka, K. Nishii, and T. Miyasaka, 2014: Impacts of a warming marginal sea on torrential rainfall organized under the Asian summer monsoon. Sci. Rep., 4, 5741, doi:10.1038/srep05741.

Takahashi, H. G., N. N. Ishizaki, H. Kawase, M. Hara, T. Yoshikane, X. Ma, and F. Kimura, 2013: Potential impact of sea surface temperature on winter precipitation over the Japan Sea side of Japan: A regional climate modeling study. $J$. Meteor. Soc. Japan, 91, 471-488.

Tsuguti, H., and T. Kato, 2014: Contributing factors of the heavy rainfall event at Amami-Oshima Island, Japan, on 20 October 2010. J. Meteor. Soc. Japan, 92, 163-183.

Utsumi, N., S. Seto, S. Kanae, E. E. Maeda, and T. Oki, 2011: Does higher surface temperature intensify extreme precipitation? Geophys. Res. Lett., 38, L16708, doi:10.1029/2011GL 048426.

Manuscript received 4 October 2014, accepted 19 December 2014 SOLA: https://www.jstage.jst.go.jp/browse/solal 